\title{
O Sujeito na Pesquisa Qualitativa: Desafios da Investigação dos Processos de Desenvolvimento
}

\author{
Cláudio Márcio de Araújo ${ }^{1}$ \\ Maria Cláudia Santos Lopes de Oliveira \\ Maristela Rossato \\ Universidade de Brasília
}

\begin{abstract}
RESUMO - O objetivo do artigo é produzir uma reflexão sobre a investigação da subjetividade, suas transformações no tempo irreversível e suas implicações para a investigação qualitativa dos processos de desenvolvimento humano. A primeira parte explora um olhar histórico-filosófico sobre os conceitos de sujeito e realidade. A parte final do texto apresenta e discute cinco desafios não superados, no contexto da pesquisa contemporânea do desenvolvimento humano, a saber: (a) o de representar fenômenos em processo de mudança; (b) o de assumir o caráter complexo da investigação de temas integradores como a subjetividade; (c) o de considerar as práticas de pesquisa como promotoras de desenvolvimento microgenético; (d) o de reconhecer o pesquisador como parte da realidade investigada, sujeito em desenvolvimento; (e) o de prover o alinhamento adequado entre teoria e metodologia.
\end{abstract}

Palavras-Chave: sujeito, pesquisa qualitativa, desenvolvimento humano

\section{The Subject in Qualitative Research: Challenges Studying Development Processes}

\begin{abstract}
The goal of this paper is to induce a reflexive stance on the subjectivity, and its transformations in irreversible time, considering its implications on qualitative studies of human development. Initially, a historical-philosophical overview of the notions of 'subject' and 'reality' are provided. In the second part of the paper, five dead-locks of contemporary research on human development are debated: (a) representing phenomena while they are changing; (b) the complexity involved in investigating integrative psychological categories - such as 'subjectivity'; (c) the assumption that research practices themselves promote dynamics of microgenetic development; (d) the recognition that researchers are a part of the investigated reality, also developing subjects; and, (e) the quest for coherence between theory and methodology, demanding non-instrumental methodological approaches.
\end{abstract}

Keywords: subject, qualitative research, human development

\section{A Construção da Noção de Sujeito}

Como um conceito historicamente delineado a noção de sujeito mudou significativamente ao longo dos séculos, desde os primeiros filósofos ocidentais até a contemporaneidade. $\mathrm{O}$ período entre o humanismo renascentista do século XVI e o Iluminismo do século XVIII, por exemplo, trouxe mudanças consideráveis nas concepções sobre o assunto. Durante esse período, emergem dois aspectos dignos de nota: o senso de individualidade, que concorreu para o surgimento da imagem de um indivíduo soberano; e a noção de razão, que levou à imagem predominante do sujeito racional.

Da mesma forma, revoluções teóricas como a que substituiu o geocentrismo pelo sistema heliocêntrico, a teoria da evolução de Darwin e a teoria marxista, estas últimas já no século XIX, representam momentos significativos para se compreender as rupturas em relação à conceituação do sujeito soberano e sua relação com o conhecimento. De acordo com Hall (2002), tais eventos contribuíram para a "descentração

1 ENDEREÇO PARA CORRESPONDÊNCIA: claudioaraujo.filo@ gmail.com do sujeito" (p.23), reduzindo a soberania da individualidade e relativizando o seu papel e a sua importância nos processos sociais.

A descoberta do sistema heliocêntrico descentralizou o sujeito, reduzindo seu lugar simbólico ao de uma minúscula parte da galáxia. A teoria da evolução de Darwin coloca o homem como simples peça de um processo evolutivo que integra todas as formas vivas e permite questionar o status da espécie humana como imagem e semelhança de Deus. Já a teoria marxista, ao situar o homem como peça na engrenagem do materialismo histórico, converte-o em produto e produtor de sua existência concreta, cuja condição subjetiva depende das condições de vida dadas pelo mundo material. Dessa forma, a razão humana deixa de ser vista como autônoma, passando a ser entendida como determinada pela realidade em meio a qual se constitui.

Ao longo da modernidade, a noção de sujeito constrói-se em meio a um conjunto de concepções nas quais o eu é visto como consciente de si e da sua capacidade de pensar. Em todo esse processo, uma figura essencial é René Descartes (1596-1650), que inicia uma nova página na história e teoria do conhecimento e que, mediante suas ideias, pode ser visto como o principal arquiteto de uma nova noção 
de eu, a qual permeará o pensamento moderno: um eu que existe no processo de pensar, ou seja, como um ser pensante. No rastro da filosofia do sujeito de Descartes, surgem modelos teóricos que têm em comum o fato de o homem ser apresentado enquanto substância pensante, criador de métodos avaliativos, capaz de alcançar verdades graças ao cogito e ao rigor metodológico que a racionalidade inerente lhe impõe (Descartes, 1962). Nessas mesmas perspectivas, o homem é capaz de produzir verdades sobre o mundo e sobre si mesmo. Portanto, para se compreender por que e para que o racionalismo triunfa na idade moderna, há que se buscar o fundamento no sujeito cartesiano, o homem considerado a fonte de todo conhecimento, dono de si, portador da verdade, sujeito da consciência (Descartes, 1993). Assim, ao racionalizar a realidade, o pensamento cartesiano racionaliza o eu, com consequências para o desenvolvimento da ciência moderna e da psicologia, em particular.

Ao longo dos séculos XIX e XX, as críticas ao racionalismo e à noção de sujeito racional foram fortalecidas pelas obras de filósofos como Kierkegaard e Nietzsche. A filosofia de Friedrich Nietzsche, de modo particular, pode ser considerada uma das críticas mais radicais à metafísica (Jardim, 2001). Nietzsche contrapõe a noção de sujeito cartesiano como substância pensante e apresenta uma genealogia do sujeito. Introduz a ideia de homem como multiplicidade de forças, em que cada sujeito representa a expressão de diversas possibilidades de vida. Dessa forma, o foco de interesse migra do processo de conhecer para o sujeito que conhece, evidenciando a subjetividade e enfatizando o papel significativo desta na produção do conhecimento. Para além da mera explicação da realidade, com a contribuição desses filósofos, o conhecimento passa a ser visto como um trabalho de interpretação e de atribuição de sentidos que leva a marca do interpretante.

Contudo, é no meio do século XX que ocorre o que consideramos uma ruptura definitiva com a visão mecanicista do mundo cartesiano, que se seguiu à quebra do paradigma newtoniano pela Teoria da Relatividade e o desenvolvimento da Física Quântica. Essa ruptura também é demarcada por contribuições de filósofos contemporâneos como Michel Foucault, Jacques Derrida, Jean Baudrillard, Paul Ricoeur, entre outros, que destacam o caráter construtivo, parcial e provisório do conhecimento. Ganham crescente destaque novas epistemologias que problematizam de modo radical a noção de sujeito cartesiano e a construção de conhecimento que ela sustenta. Assim, metodologias positivistas começam a se revelar insuficientes na orientação da discussão daquilo que diz respeito ao domínio do humano (Flick, 2004; Mancebo, 2004; Morin, 1996). As abordagens emergentes apresentam uma ideia de sujeito como sistema aberto e complexo, concebido como múltiplo, descentrado e em desenvolvimento dialógico.

O desenvolvimento da psicologia como ciência moderna não segue outro caminho. Nesse desenvolvimento, destacamse os pensamentos de Wilhelm Wundt (1832-1920) e William James (1842-1910), considerados, conforme o contexto sociocultural alemão ou estadunidense, os fundadores da psicologia moderna. Interessante notar que não se passaram mais de trinta anos entre a publicação da obra desses autores e os eventos que condicionaram a transferência para as universidades norte-americanas de inúmeros e importantes pensadores da psicologia europeia perseguidos pelo nazismo. Nesse processo, parte da base epistemológica inicial da psicologia - que prezava conceitos como gênese, estrutura, e qualidade - perdeu espaço para modelos de pensamento objetivistas, que se tornaram predominantes a partir de então (Lopes de Oliveira, 2016).

Entretanto, em ambos os fundadores, encontram-se indicadores de desenvolvimento teórico que apontam tanto para a psicologia moderna - e seu projeto de afirmação cientificista como ciência natural experimental - como para uma visão contemporânea de homem. Em outras palavras, de acordo com Lopes de Oliveira (2016), ainda que James e Wundt sejam mais reconhecidos por sua contribuição à psicologia experimental, ambos deixaram legados à psicologia cultural, em geral, pouco destacados pelos historiadores da psicologia. De Wundt, há a obra densamente elaborada (10 volumes) denominada Volkerpsychologie (A Psicologia dos Povos), em que trata de temas como a evolução psíquica dos povos, a vida humana em coletividade e outros, em que ressalta a unidade dialética sujeito-contexto (Ericeira, 2007). No que se refere a W. James, sua clássica obra Principles of Psychology (James, 1952/1890) traz um debate singular sobre a categoria de self, que será densamente explorada por diferentes autores.

Considerando-se a posição acima, o sujeito não é tão simplesmente uma máquina de pensar, mas é fenômeno, mudança, processo, tempo. Um eu que é fluxo do pensamento e processo relacional - perspectiva diametralmente oposta e que rompe com uma visão metafísica do eu. O sujeito perde o status de substâncias mental e material (fixas, eternas) e passa a ser fenômeno (mutável, finito).

Estava, desse modo, aberto o caminho para que perspectivas inovadoras tomassem as contribuições do pensamento crítico e suas implicações metodológicas na fundamentação da compreensão dos processos de desenvolvimento da pessoa e da subjetividade. É importante salientar que as primeiras matrizes teóricas que deram origem à psicologia do desenvolvimento (cf. Heinz Werner, James Baldwin, Pierre Janet) compartilhavam dessa visão de homem, de acordo com a qual o sujeito da psicologia do desenvolvimento é um ser em movimento, em perene construção no tempo irreversível. A crescente hegemonia dos modelos psicológicos objetivistas, ao longo do século $\mathrm{XX}$, refletiu-se na psicologia do desenvolvimento na forma de teorias universalistas, normativas, prescritivas (Castro, \& Souza, 1994 ordem dos autores trocadas). Nas últimas décadas, os primeiros modelos compreensivos do sujeito psicológico têm sido retomados e investigados, especialmente, em meio à epistemologia qualitativa (Souza, Branco, \& Lopes de Oliveira, 2008).

O desafio da epistemologia qualitativa nos conduz a explorar o espelho duplo da subjetividade na construção do conhecimento em pesquisa psicológica, em que se incluem o sujeito participante da pesquisa e o sujeito pesquisador. A coordenação intersubjetiva e a transação dialógica explícita ou implícita entre eles reportam à importância das escolhas teóricas, metodológicas e éticas que orientam uma investigação. Considerando que a noção de sujeito que se assuma impõe limites e possibilidades no desenvolvimento de 
uma pesquisa, além de direcionar relações entre pesquisador e participantes da pesquisa, julgamos necessária uma reflexão mais profunda sobre a noção de sujeito que perpassa e sustenta os pressupostos teóricos e metodológicos da pesquisa qualitativa, na atualidade.

\section{A Noção de Realidade na Pesquisa Qualitativa}

Ontologicamente, a realidade constitui-se por diferentes modos de compreensão: a realidade objetiva, tangível, externa ao sujeito e com possibilidade de ser completamente conhecida; a realidade percebida, que não poderia ser conhecida totalmente, mas tão somente percebida em determinados ângulos; a realidade construída, resultado de uma construção na mente das pessoas, oferecendo dúvidas à sua existência com possibilidade de ser completamente conhecida e, sendo assim, a realidade seria uma construção complexa de múltiplas realidades; a realidade criada, partindo do pressuposto de que a realidade não existe como tal, que se trataria de uma probabilidade matemática, do mundo subatômico, das partículas; a realidade virtual, como aquilo que tem uma existência aparente e não real, atribuída ao universo das tecnologias da informação e comunicação (Bolívar, 2008; Lincoln \& Guba, 1985).

A natureza de uma pesquisa - quantitativa, qualitativa, multimétodo - constitui-se, em essência, pela ontologia de realidade que orienta a construção do problema de pesquisa, constituindo o objeto a ser estudado. A pesquisa qualitativa caracteriza-se como um processo de interpretação e compreensão, não se contentando com a simples explicação das realidades. Desse modo, "[a] realidade estudada pela pesquisa qualitativa não é uma realidade determinada, mas é construída por diferentes 'atores"' (Flick, 2004, p. 43). A realidade social é vista como uma construção dinâmica e complexa, impossível de ser apreendida, de uma vez por todas pelo pesquisador, tal como se fosse uma coisa, mas é interpretada e compreendida em um processo histórico, sistêmico e contextualizado. $\mathrm{O}$ caráter construtivo da realidade social, o destaque ao caráter processual e reflexivo do saber e a importância da realidade objetiva nos significados subjetivos são fundamentos teóricos na caracterização da pesquisa qualitativa (Flick, Von Kardorff, \& Steinke, 2000). Segundo Minayo (1993):

a pesquisa qualitativa responde a questões muito particulares. Ela se preocupa, nas ciências sociais, com um nível de realidade que não pode ser quantificado, ou seja, ela trabalha com o universo de significados, motivos, aspirações, crenças, valores e atitudes, o que corresponde a um espaço mais profundo das relações dos processos e dos fenômenos que não podem ser reduzidos à operacionalização de variáveis. (p. 21)

González Rey $(2002,2003$, 2005) concebe que o pesquisador não se apropria da realidade, mas gera inteligibilidade no conjunto das informações produzidas na pesquisa, amparado pelo seu aporte teórico, produzindo zonas de sentido, que conferem valor ao conhecimento por sua "capacidade de gerar campos de inteligibilidade que possibilitem tanto o surgimento de novas zonas de ação sobre a realidade, como de novos caminhos de trânsito dentro dela através de nossas representações teóricas" (González Rey,
2005, p. 6). O aporte teórico do pesquisador é a ferramenta constitutiva da base que lhe possibilita fazer a construção da realidade na pesquisa. Pesquisar o desenvolvimento tendo como referência uma abordagem psicanalítica, históricocultural ou sistêmica, sem gerar nenhuma hierarquia da importância das mesmas, representa olhares diferentes sobre a realidade dos indivíduos, implicando argumentos próprios sobre o fenômeno.

A pesquisa qualitativa se caracteriza pela busca, como princípio do conhecimento, de uma compreensão das complexas relações constituintes da realidade social. Ela parte da ideia de realidade como construção e "consiste em um conjunto de práticas materiais e interpretativas que dão visibilidade ao mundo" (Denzin \& Lincoln, 2006, p. 17). O desafio de estudar os processos dinâmicos da vida humana em sua complexidade gera um obstáculo epistemológico, que precisa ser transposto, diante do desgaste axiomático da compreensão do sujeito e sua realidade. Registra-se uma "inadequação entre seus pressupostos básicos e a natureza dos fenômenos sob estudo" (Valsiner, 2012, p. 297), exigindo que o domínio metodológico seja revisto.

Como se pode identificar, as abordagens qualitativas de pesquisa tampouco constituem um campo consensual. Ao longo da história das práticas de pesquisa, segundo Chizzotti (2003, 2006), o desenvolvimento do paradigma qualitativo foi marcado por rupturas e reconstruções, não havendo o progresso acumulado. Desse modo, a abordagem qualitativa "abriga tensões teóricas subjacentes que, cada vez mais, a distanciam de teorias, práticas e estratégias únicas de pesquisa" (Chizzotti, 2003, p. 223). Trata-se de um cenário dotado de grande complexidade, no qual o objeto em estudo tem papel central na articulação necessária entre as concepções implícitas do pesquisador, a teoria e a metodologia.

\section{Desafios da Investigação Qualitativa dos Processos de Desenvolvimento do Sujeito}

A noção de um sujeito que se expressa, compreende, interage e interpreta, traz impactos significativos para as ciências humanas e, em especial, para a psicologia do desenvolvimento. Abrindo mão completamente da separação objetiva entre pesquisador e objeto de pesquisa, de acordo com a perspectiva contemporânea das ciências humanas que abraçamos, a compreensão do fenômeno psicológico demanda que dialoguemos com ele, preservando sempre o espaço para que o sujeito se expresse. O objeto de estudo da psicologia do desenvolvimento é, portanto, o sujeito de signos, em transformação, um sujeito portador de voz que se forma e se modifica em meio a relações dialógicas (Bolívar, 2001; Connelly \& Clandinin, 1990; Freitas, 2002). E essas relações dialógicas dão origem a modos cada vez mais complexos de constituição e organização da subjetividade.

Compreender o desenvolvimento nessa perspectiva contemporânea é reconhecer a mediação da cultura na construção do self. O que significa despir o sujeito das clássicas relações lineares de causalidade entre psique e comportamento e reconhecê-lo como um ser histórico, singular em permanente construção e reconstrução. Tal 
processo se dá no âmbito de diversos contextos socioculturais e esses muitos contextos influenciam e são modificados numa relação dialógica de trocas recíprocas entre pessoa e ambiente. Essa relação de coconstrução justifica a importância de aprofundarmos este espelho duplo da subjetividade na construção do conhecimento em pesquisa psicológica qualitativa, reconhecendo o papel ativo dos sujeitos - pesquisador e participante - no processo da investigação. Sujeitos que se comunicam, criam enredos da própria história e se transformam na interação, produzindo conhecimento e eventos de desenvolvimento.

Numa perspectiva psicológica desenvolvimental, o ponto de vista do sujeito é colocado em primeiro plano e, assim, ele tem propriedade para narrar a própria história. Como destacam Labov e Waletsky, em seu texto clássico de 1967, narrativas são versões orais de experiências vividas. A influência inspiradora desses autores, entre outros, tem levado a uma crescente compreensão do valor heurístico do estudo dos processos subjetivos por meio de narrativas. Segundo Delory-Momgerger (2008, p.37), "não fazemos a narrativa de nossa vida porque temos uma história; temos uma história porque fazemos a narrativa de nossa vida". Ao se expressar, o sujeito coloca-se simultaneamente em relação com o outro, com o contexto e consigo mesmo, em um processo que favorece sua compreensão dos eventos vividos e a construção de conhecimentos e significados acerca de suas experiências pessoais. Nas palavras de Barthes (1976), "[o] ser humano é essencialmente um contador de histórias que extrai sentido do mundo através das histórias que conta" (p. 25).

A ideia de sujeito como narrador de si e do mundo também encontra fundamentos no pensamento de Bakhtin (1895-1975), autor que enfatiza ser possível a compreensão do sujeito, de sua história e de sua vida cotidiana, mediante os textos que ele cria e oferta ao outro na comunicação, convertendo-os em signos compartilhados. Bakhtin sustenta o dialogismo como o fundamento e princípio mesmo da consciência. Segundo ele, "[a] própria consciência só pode surgir e se afirmar como realidade mediante a encarnação material em signos" (Bakhtin, 1988, p. 33).

Segundo a perspectiva dialógica inaugurada por Bakhtin e objeto da reflexão de diversos autores contemporâneos que têm contribuído para a reflexão na psicologia do desenvolvimento (Hermans, 2002; Marková, 2003; Salgado, Cunha, \& Bento, 2013; Valsiner, 2012; Zittoun, 2012), é coerente afirmar que nós, seres humanos, pensamos, construímos signos e transformamos pensamentos mediante interações com o pensamento dos outros. Assim, nossa voz é carregada de outras vozes, as vozes e experiências alheias penetram as nossas próprias, que somente existem e ganham sentido quando relacionadas ao outro (Bakhtin, 1992).

Araújo e Lopes de Oliveira (2010, 2013), seguindo autores de base histórico-cultural, defendem que se consideramos a subjetividade como constitutiva da pessoa, o foco sobre esta deve perpassar as práticas de pesquisa qualitativa, tornando-se um aspecto especialmente relevante para as que são realizadas no campo do desenvolvimento humano. A seguir, apresentamos alguns desafios importantes que se colocam para a pesquisa em desenvolvimento humano, com forte impacto sobre os desenhos metodológicos que se venha a adotar.
O primeiro desafio da investigação qualitativa dos processos de desenvolvimento do sujeito é o de representar fenômenos em processo de mudança, ou seja, o de abordar dinamicamente os eventos em análise, sem converter fluxo em estado ou filme em fotografia, e, ainda, procurando preservar a centralidade da dimensão do tempo na constituição do objeto da psicologia do desenvolvimento. Este tem sido um nó que a área não desistiu de desatar (Cole \& Cole, 2003).

Na história das práticas de pesquisa na área, esse problema levou ao aperfeiçoamento dos dispositivos de registro, a exemplo do uso de videogravação em estudos observacionais. Com o dispositivo de filmagens, visava-se melhor recuperar o processo de emergência, desaparecimento ou transformação de funções, no tempo, com a possibilidade de se rever as cenas. $\mathrm{O}$ aprimoramento das práticas de pesquisa, igualmente, contribuiu para o avanço das abordagens microanalíticas, implicadas na apreensão do momento preciso do desenvolvimento das funções. Entretanto, não se têm estratégias de investigação suficientemente aprimoradas para captar o transcurso do tempo e seu impacto sobre os processos de mudança quando se tomam por foco fenômenos relacionados a cortes temporais mais amplos, a exemplo dos processos ontogenéticos, na sua totalidade.

De certo modo, a questão transparece também no desenho dos estudos de corte longitudinal, cujos programas investigativos favorecem a comparação entre dois ou mais estados do processo distribuídos, no tempo, sem propriamente, a nosso ver, possibilitar o acesso ao fenômeno do desenvolvimento da estrutura propriamente dito. Estudo desenvolvido por Rossato (2009), numa análise longitudinal sobre o desenvolvimento da subjetividade no processo de superação das dificuldades de aprendizagem, evidencia que as mudanças no curso de desenvolvimento da subjetividade são identificáveis, porém o fator desencadeador dessas mudanças acaba sendo sempre uma interpretação do pesquisador a partir das informações produzidas no curso da pesquisa. $O$ participante, por mais esforço que tente empreender, ao fazer uma busca retrospectiva do fator desencadeador das mudanças, produz um olhar do presente para o passado, momento em que seu olhar também é uma interpretação do processo vivido. Captar o transcurso do tempo no desenvolvimento do sujeito é um desafio para a pesquisa a exemplo do desafio que é para o próprio sujeito captar os elementos microgenéticos constituidores do seu desenvolvimento. A pesquisa sobre o desenvolvimento visa compreender os "processos de construção dos sujeitos que se constroem ao construir práticas, conhecimento, cultura, dinâmicas sociais" (Schinitman \& Fuks, 1996, p. 249).

É importante destacar também, entre os aspectos sensíveis da pesquisa em desenvolvimento humano, como um segundo desafio, a complexidade que a investigação assume quando toma por objeto de análise categorias psicológicas integradoras, a exemplo de personalidade, psiquismo ou subjetividade. Nesses casos, o caráter imaterial - caracteristicamente semiótico - do objeto em análise exige do pesquisador adotar estratégias e dispositivos múltiplos de construção e análise de informações de pesquisa, tendo claro o caráter reconstrutivo da análise, que atua como uma operação de recriação do objeto. Esses objetos não podem ser esgotados em sua investigação pelo comportamento 
observável, a exemplo do que parte da tradição dos estudos em psicologia adotou. Para Vygotski, a psique é um sistema de reflexos não manifestos e, diante disso, seria um "suicídio para a ciência renunciar a investigá-la indiretamente através de seu reflexo em outros sistemas de reflexos" (Vygotski, 1991, p. 52).

A compreensão de categorias psicológicas integradoras impõe descobrir os processos psíquicos complexos entranhados nos comportamentos e, ao mesmo tempo, saber considerá-los em sua organicidade. A complexidade existe em situações que se produza um "emaranhamento de ações, de interações, de retroações” (Morin, 1996, p. 274). Entretanto, tem-se ainda outro desafio na presente discussão: com que complexidade o pesquisador estuda seu objeto? "Cremos ver a realidade; em realidade vemos o que o paradigma nos pede para ver e ocultamos o que o paradigma nos impõe a não ver" (Morin, 1996, p. 276). Olhar de frente, enfrentando a desordem e a incerteza, é o caminho para a compreensão dos sujeitos como seres de natureza multidimensional.

Um terceiro desafio configura-se pelo fato de que a investigação não apenas retrata processos de mudança, mas, muitas das vezes, as práticas de pesquisa promovem dinâmicas de desenvolvimento microgenético. Para a compreensão desse quadro, muito contribuem os estudos com entrevistas, baseados em narrativas, conforme abordamos anteriormente. Conforme Lopes de Oliveira (2006, 2003) e Souza et al. (2008), a entrevista é uma oportunidade para a experiência auto-epistêmica. Os vários níveis de comunicação entre entrevistado e entrevistador podem dar a conhecer, a ambos, distintas dimensões de própria subjetividade. Conduzir o participante da pesquisa a uma reflexão abre possibilidades de produção de novos sentidos subjetivos que se integram ao sistema de sentidos já configurados, conduzindo a momentos qualitativos de desenvolvimento do próprio sistema. "A constituição do sentido subjetivo da experiência no sujeito é um processo complexo, que se produz como um momento da cultura, individual e irrepetível na história do sujeito concreto" (González Rey, 2003, p. 57).

Nenhuma pesquisa é neutra ao participante ou ao pesquisador. A pesquisa coloca o sujeito diante de reflexões pessoais, que envolvem dinâmicas simbólico-emocionais em construção e reconstrução na vivência da pesquisa, provocando dinâmicas de desenvolvimento microgenético. Esse fator, para alguns objetos de pesquisa, pode não ser uma variável tão significativa, entretanto, quando o objeto é o desenvolvimento do sujeito, temos um objeto em que a própria vivência da pesquisa vai modificando-o ao longo do processo. Evidentemente essa dinâmica somente vai configurar-se se o participante estiver efetivamente implicado emocionalmente na pesquisa, condição essencial para o estudo de categorias psicológicas.

Seguindo a linha de pensamento anterior, o que configura um quarto desafio nas pesquisas em desenvolvimento humano é o reconhecimento do pesquisador como parte da realidade investigada e sujeito em desenvolvimento. O pesquisador é parte da realidade investigada. Ao contrário de uma pretensa neutralidade do pesquisador nas ciências, as abordagens que concebem o conhecimento como resultado de uma construção do pesquisador elevam a compreensão desse papel à de protagonista, reconhecendo seu papel ativo na pesquisa. Valsiner (2012, p. 3010) afirma que "os cientistas não são seres humanos racionais, mas seres humanos subjetivos, pessoalmente envolvidos, com preferências subjetivas e posições, a partir dos quais consideram os assuntos de sua pesquisa".

Ao produzir inteligibilidade sobre os fenômenos estudados, o pesquisador também pode estar evocando o próprio desenvolvimento microgenético. Suas escolhas, sua história e posicionamentos estão em constante diálogo com o contexto de pesquisa e devem ser considerados no momento de construção e análise das informações. Nessa relação dialógica e colaborativa considera-se que tanto o pesquisador como o sujeito pesquisado possuam vozes ativas e dialoguem entre si e com os seus vários contextos, estando em constante transformação e aprendizagem, no processo de pesquisa.

De acordo com as vertentes das ciências humanas alinhadas com o paradigma qualitativo, o sujeito pesquisador não é um observador externo, um fotógrafo do fenômeno, ele está localizado no mundo que pesquisa. Seu papel é o de compreender e interpretar o objeto de pesquisa, e, para isso, precisa conferir grande ênfase ao contexto, bem como aos significados que nele são explicitados (Bolívar, 2001; González Rey, 2002; Günther, 2006). Para cumprir tal papel é importante que se explore uma variedade de práticas interpretativas, considerando-se que a diversidade de práticas contribui para revelar diferentes facetas do objeto em estudo, possibilitando uma compreensão mais aprofundada do fenômeno (Denzin \& Lincoln, 2006).

$\mathrm{O}$ quinto desafio que apresentamos relativo às pesquisas dos processos de desenvolvimento do sujeito pauta-se pelo necessário alinhamento entre teoria e uma metodologia não-instrumentalista que ultrapasse a visão do acúmulo de dados. Os processos de desenvolvimento se expressam de modo singular no sujeito e não podem ser engessados em metodologias pouco sensíveis à complexidade que lhe é inerente. $\mathrm{O}$ que define o alinhamento entre teoria e metodologia é essencialmente o que se pretende investigar com a pesquisa.

As teorias são explicações mais gerais sobre os objetos, sempre abertas e em construção. Todo avanço qualitativo no estudo dos problemas se caracteriza pelo desenvolvimento teórico, pela produção de novos aportes que possibilitam gerar inteligibilidade e abertura de novas zonas de sentido sobre a realidade estudada. O pesquisador é o sujeito da construção teórica ao desenvolver suas ideias dentro do marco de uma teoria concreta, conservando a possibilidade de contradições e discrepâncias entre seus pensamentos e a teoria (González Rey, 2002).

Pesquisador e participantes não são prisioneiros do instrumental metodológico, ativamente se expressam como sujeitos na pesquisa e isso deve ser considerado como parte do processo da investigação. Os instrumentos da pesquisa não estão em busca de respostas prontas, mas devem possibilitar a reflexão e a expressão singular dos participantes. Nessa abordagem, o qualitativo está na qualidade do conteúdo expresso, via interação dialógica com o pesquisador, abrindo janelas interpretativas do fenômeno estudado, orientadas pelos objetivos da pesquisa. A pesquisa de Rossato (2009), já citada anteriormente, é um exemplo do exercício de construir 
instrumentos particulares para cada participante da pesquisa, respeitando as formas mais criativas de expressão de estudantes que apresentavam dificuldades de aprendizagem escolar. Essa prática esteve pautada pelo pressuposto de que mais importante do que identificar o que o participante é capaz de expressar diante de um instrumento padronizado, é identificar que instrumentos são mais adequados para mobilizar a expressão do participante. A qualidade das informações produzidas no processo da pesquisa contém maior relevância do que os recursos utilizados no estudo do desenvolvimento, que sempre é pautado pela singularidade dos processos vividos pelos sujeitos.

\section{Considerações Finais}

Esses são desafios que nos são colocados quando assumimos uma noção de sujeito que considera o papel constitutivo da história e da cultura nos processos psicológicos humanos. A investigação e discussão da emergência e do desenvolvimento do sujeito, bem como as escolhas teóricometodológicas devem estar coerentes com os pressupostos que fundamentam a pesquisa qualitativa e, consequentemente, uma noção de sujeito.

Um sujeito que só pode ser compreendido como relação dialógica e contextualizada entre objetividade e subjetividade, não podendo ser reduzido a nenhuma dessas dimensões. Como síntese inacabada revela suas perspectivas e seu ineditismo na relação entre significações e ações, na singularização do coletivo, emocionalmente afetado pelas suas relações com o mundo.

Embora não exclusivas da pesquisa qualitativa, essas discussões partem de uma noção específica de sujeito, que se revela na construção dos papeis de pesquisador e pesquisado, concebidos como coconstrutores do conhecimento. Os sujeitos em interação na pesquisa produzem e, ao mesmo tempo, são constituídos por ela mediante relações dialógicas, situadas e complexas (Bruner, 1991; Freitas, 2002). Dessa forma, a noção de sujeito compartilhada pela perspectiva dialógica contrapõe-se fortemente às visões reducionistas empiristas e idealistas - as quais se sustentam em um sujeito fechado em si mesmo, contido e divorciado da realidade. Nutre-se a compreensão de que o sujeito configura-se no diálogo - com os outros e consigo mesmo -, de acordo com uma dinâmica complexa e imbricada, que se desenrola no tempo e no espaço, sempre mediada por signos da cultura.

\section{Referências}

Araújo, C. M., \& Lopes de Oliveira, M. C. S. (2010). Significações sobre desenvolvimento humano e adolescência em um projeto socioeducativo. Educação em Revista, 26(03), 169-194.

Araújo, C. M., \& Lopes de Oliveira, M. C. S. (2013). Contribuições de Bourdieu ao tema do desenvolvimento adolescente em contexto institucional socioeducativo. Pesquisas e Práticas Psicossociais, 8(2), 215-224.

Barthes, R. (1976). Introdução à análise estrutural da narrativa. In R. Barthes, Análise estrutural da narrativa: Pesquisas semiológicas (pp. 19-60). Petrópolis: Vozes.
Bakhtin, M. (1988). [Volochinov, V.] Marxismo e filosofia da linguagem. São Paulo: Hucitec.

Bakhtin, M. (1992) Estética da criação verbal. São Paulo: Martins Fontes.

Bolívar, A. (2001). Profissão professor: O itinerário profissional e a construção da escola. Porto Alegre: EDIPUCRS.

Bolívar, C. R. (2008). El enfoque multimétodo en la investigación social y educativa: Una mirada desde el paradigma de la complexidad. Revista de Filosofía y Socio Política de la Educación, 8(4), 13-28

Bruner, J. S. (1991). The narrative construction of reality. Critical Inquiry, 18, 1-20.

Castro, L. R., \& Souza, S. J. (1994). Desenvolvimento humano e questões para um final de século: Tempo, história e memória. Psicologia Clínica, 6(6).

Chizzotti, A. (2003). A pesquisa qualitativa em ciências humanas e sociais: Evolução e desafios. Revista Portuguesa de Educação, 16(2), 221-236.

Chizzotti, A. (2006). Pesquisa em ciências humanas e sociais. São Paulo: Cortez.

Cole, M., \& Cole, S. (2003). O desenvolvimento da criança e do adolescente. Porto Alegre: Artmed.

Connelly, F. M., \& Clandinin, J. (1990). Stories of experience and narrative inquiry. Educational Researcher. 5(19), 2-14.

Delory-Momgerger, C. (2008). Les histoires de vie: De l'invention de soi au projet de formation. Paris: Anthropos.

Denzin, N. K., \& Lincoln, Y. S (2006). O Planejamento da pesquisa qualitativa: Teorias e abordagens. Porto Alegre: Artmed.

Descartes, R. (1962). Obra escolhida. (J. Guinsburg \& B. Prado Júnior, Trad.). São Paulo: Difusão Europeia do livro.

Descartes, R. (1993). Discurso do método. (A. Morão, Trad.): Lisboa.

Ericeira, R. C. S. (2007, Outubro). História e vida mental: A psicologia dos povos Wundtiana. Trabalho completo apresentado no $14^{\circ}$ Encontro Nacional da ABRAPSO, Rio de Janeiro, Brasil.

Flick, U. (2004). Uma introdução à pesquisa qualitativa. Porto Alegre: Artmed.

Flick, U., von Kardorff, E., \& Steinke, I. (2000). (Orgs.). Was ist qualitative Forschung? Einleitung und überblick. In U. Flick, E. von Kardorff, \& I. Steinke (Orgs.), Qualitative forschung: Ein handbuch (pp. 13-29). Reinbek: Rowohlt.

Freitas, M. T. A. (2002). A abordagem sócio-histórica como orientadora da pesquisa qualitativa. Cadernos de Pesquisa, 116, 21-39.

Gonzalez Rey, F. (2002). Pesquisa qualitativa em psicologia: Caminhos e desafios. São Paulo: Thomson.

González Rey, F. (2003). Epistemología cualitativa y subjetividad. São Paulo: EDUC.

González Rey, F. (2005). Pesquisa qualitativa e subjetividade: Os processos de construção da informação. Thomson: São Paulo.

Günther, H. (2006). Pesquisa qualitativa versus pesquisa quantitativa: Esta é a questão?. Psicologia: Teoria e Pesquisa, 22(2), 201-210.

Hall, S. (2002). Identidade cultural na pós-modernidade. Rio de Janeiro: DP\&A.

Hermans, H. J. M. (2002). The Dialogical self as a society of mind: An introduction. Theory and Psychology, 12(2), 147-160. 
James, W. (1952). The principles of psychology (Great books of the western world, Vol. 53). Chicago: Enciclopaedia Britannica. (Original publicado em 1890)

Jardim, A. F. C. (2001). Morte do homem, morte do sujeito: Nietzsche e a crítica à metafísica da subjetividade em Descartes. Unimontes Científica, 2(2), 1-22.

Labov, W. \& Waletzky, J. (1967). Narrative analysis: Oral versions of personal experience. In J. Helm (Org.), Essays on the verbal and visual arts (pp. 12-44). Seattle: University of Washington Press.

Lincoln Y. S., \& Guba, E. G. (1985). Naturalistic inquiry. Beverly Hills, CA: Sage.

Lopes de Oliveira, M. C. S. (2003). Subjetividade e conhecimento: Do sujeito da representação ao sujeito dialógico. Fractal: Revista de Psicologia, 15(2), 33-52.

Lopes de Oliveira, M. C. S. (2006). Identidade, narrativa e desenvolvimento na adolescência: Uma revisão crítica. Psicologia em Estudo, 11(2), 427-436.

Lopes de Oliveira, M. C. S. (2016). Desenvolvimento do self e processos de hiperindividualização: Interrogações à psicologia dialógica. Revista Psicologia USP.

Mancebo, D. (2004). Indivíduo e Psicologia: Gênese e desenvolvimentos atuais. In D. Mancebo \& A. M. Jacó-Vilela (Orgs.), Psicologia social: Abordagens sócio-históricas e desafios contemporâneos (pp. 35-48). Rio de Janeiro: EdUERJ.

Marková, I. (2003). Dialogicality and social representations: The dynamics of mind. Cambridge: Cambridge University Press.

Minayo, M.C.S. (1993).Pesquisa social: Teoria, método e criatividade. Rio de Janeiro: Vozes.
Morin, E. (1996). A noção de sujeito. In D. F. Schnitman (Org.), Novos paradigmas, cultura e subjetividade (J. H. Rodrigues, Trad., pp. 45-55). Porto Alegre: Artes Médicas.

Rossato, M. (2009). O movimento da subjetividade no processo de superação das dificuldades de aprendizagem escolar (Tese de doutorado não publicada). Universidade de Brasília, Brasília, Distrito Federal, Brasil. Recuperado de http://bdtd. bce.unb.br/tedesimplificado/tde_arquivos/45/TDE-2010-1124T173440Z-5279/Publico/2009_MaristelaRossato.pdf

Salgado, J., Cunha, C., \& Bento, T. (2013). Positioning micronalysis: Studying the self through the exploration of dialogical processos. Integrative Psychological and Behavioral Sciences, 47(3), 325-53.

Souza, T. Y., Branco, A. U., \& Lopes de Oliveira, M. C. S. (2008). Pesquisa qualitativa e desenvolvimento humano: Aspectos históricos e tendências atuais. Fractal: Revista de Psicologia, 20(2), 357-376.

Schinitman, D. F., \& Fuks, S. L. (1996). Metáforas da mudança: Terapia e processo. In D. F. Schinitman (Org.), Novos paradigmas, cultura e subjetividade (pp. 244-253). Porto Alegre: Artmed.

Valsiner, J. (2012). Fundamentos da psicologia cultural: Mundos da mente, mundos da vida. Porto Alegre: Artmed.

Vygotski, L. S. (1991) Obras escogidas (Vol. 1). Madrid, Espanha: Visor.

Zittoun, T. (2012). On the emergence of the subject. Integrative Psychological and Behavioral Science, 46(3), 259-273. 